Www.jmscr.igmpublication.org

Index Copernicus Value: 79.54

ISSN (e)-2347-176x ISSN (p) 2455-0450

crossrefDOI: https://dx.doi.org/10.18535/jmscr/v7i3.142

\title{
Assessment of Nutritional Status of Adolescent population in the Rural Field Practice Area of Sikkim Manipal Institute of Medical Sciences
}

\author{
Authors \\ Nishant Kumar ${ }^{1}$, VK Mehta ${ }^{2}$, Sumit Kar ${ }^{3}$ \\ ${ }^{1}$ Post Graduate Tutor, ${ }^{2}$ Dean \& Professor, ${ }^{3}$ Professor \\ Department of Community Medicine, Sikkim Manipal Institute of Medical Sciences, \\ Sikkim Manipal University, $5^{\text {th }}$ Mile Tadong, Gangtok
}

\begin{abstract}
Introduction: Adolescence is a critical stage of the life cycle in one's life. The presence of malnutrition during this stage of the life cycle can seriously hamper one growth and development and may deprive the nation of its demographic dividend.

Methodology: A descriptive cross-sectional study was done among 300 adolescent residing in the rural field practise area of SMIMS.

Results: The study found that $21.7 \%$ of adolescent had thinness while $13 \%$ were overweight/ obese. The odds of thinness were found to be higher among females, and those who were SC by caste. It was seen that socioeconomic status (middle class and below), and social problems in the family are strong predictors for thinness. Adolescent belonging to early adolescent age group (10-14 years), males and those who were $O B C$ by caste had higher odds of being overweight/obese. It was seen that poor lifestyle habits such as inadequate physical activity, increase consumption of junk food and higher screen time daily are strong predictors for overweight and obesity.

Conclusion: The study finds that adolescent study participant in the field practice area of SMIMS suffers from the dual burden of malnutrition. Females and Socioeconomic determinants are important ecological factors for thinness while poor lifestyle habits are an important predictor for the development of obesity and overweight among the study population.

Keywords: Adolescent, Nutritional Status, Rural area, Sikkim, India.
\end{abstract}

\section{Introduction}

Adolescent "An Age of Opportunity" a pivotal time in individual's life to build upon the development of the first decade, navigate the risk and vulnerabilities and to set upon the path to fulfilling their potential ${ }^{[1]}$. The United Nation Organisation defines an individual between age 10-19 years as an adolescent ${ }^{[2] .}$. Early (10- 14 years) and Late adolescent (15-19 years) are the two distinct stages of this part of the life cycle ${ }^{[1]}$. It is vital that at this difficult stage they have a safe environment in which they can have good cognitive, emotional, social and psychological transformation are not forced into adult roles and have full support at home, school and in the community. "Adolescence" is the age of opportunities for those withstanding these risk make their way in the world of work and further 
education. They develop their own identity and start engaging with the world around them and shaping it for the better future.Nutrition is the foundation for human development by reducing susceptibility to infection, reducing morbidity, disability and mortality. Proper nutrition enhances lifelong learning capacity and adult productivity [3]. The nutritional vulnerability is high during the adolescent period. During this period of life cycle exposure to undernutrition, micronutrient deficiency, and obesity is common. Inadequate nutrition during this critical phase of the life cycle will retard the physical and sexual maturation.

Adolescent population in India is 243 million constituting $21.4 \%$ of the total population ${ }^{[4]}$. India lives in its villages despite the sharp decline in the growth rate of

\section{Objectives}

The primary objective to the present study was to assess the nutritional status of adolescent population residing the rural field practice area of SMIMS and to study various ecological factors related to malnutrition and their association if any.

\section{Materials and Methods}

This community based descriptive cross sectional study was done among adolescent population residing in the rural field practice area of SMIMS from January 2017 to December 2017. The study protocol was submitted to the Research Protocol Evaluation Committee (RPEC) and Institutional Ethics Committee (IEC) of SMIMS for approval. The study was carried out after approval from the committee Adolescents whose parents gave consent for the study were included in the study. A sample size of 300 adolescent was selected using the formula $4 \mathrm{pq} / \mathrm{d}^{2}$, assuming the prevalence of undernutrition to be $40 \%$ based on study done Dey et al ${ }^{[14]}$.in the rural block of Darjeeling, with 95\% C.I and $15 \%$ relative precision and considering $10 \%$ non-response rate. A four stage sampling methods was carried out to collect the desired sample from a sampling frame of 5183 adolescents living at 1197 households in the rural field practices area of SMIMS (Figure 1). The selected household were visited and purpose of the study was explained to them verbally in the local language and informed written consent was taken the parents and assent was obtained from the study participants. Data collected was entered into pre tested pre designed questionnaire. General physical examination, anthropometric measurement, and systemic examination was done and BMI for age and $\mathrm{Z}$ score calculated.

\section{Results}

Majority (65.3\%) of study participants had normal nutritional status followed by thinness (21.7\%) and overweight/ obesity (13\%) (Graph 1). The odds of thinness were found to be higher among females, and SC status (Table 1). On building model using hierarchal binary logistic regression it was seen that lower socioeconomic status and social problems in the family are strong predictors for thinness. The model had the Negelkerke $\mathrm{R}^{2}$ value of 0.49 . The ROC curve (

Figure 2) for this model for thinness showed the AUC to be 0.894 .

Further participants in early adolescent age group, males and those who were OBC by caste had higher odds of being overweight/obese. On building model using hierarchical binary logistic regression

Table 2) it was seen that poor life style habits such as inadequate physical activity, increase consumption of junk food and higher screen time daily are strong predictors for overweight and obesity. The Negelkerke $\mathrm{R}^{2}$ for the model was 0.436. The ROC curve for this model showed a AUC of 0.89 (Figure 3). 
Figure 1: Graphical representation of Multi stage sampling done for the Study

A Sampling Frame of 5183 adolescents living in 1197 household under care of 9 health centre ( 1 PHC and 8 PHSC)

Stage 1 - Simple random sampling

Five health care centre were randomly chosen by simple random sampling (lottery method).

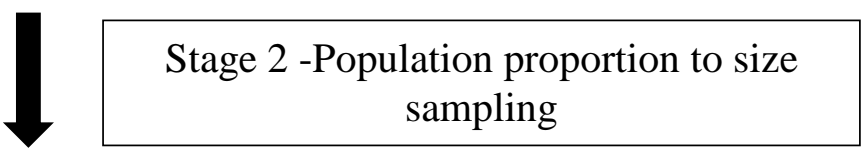

Total number adolescents population to be enrolled in the study from each subcentre was calculated using PPS method

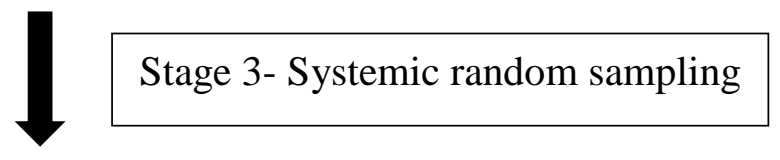

A line listing of all households with adolescent population in the chosen health care facility is made and households are chosen by systematic random sampling

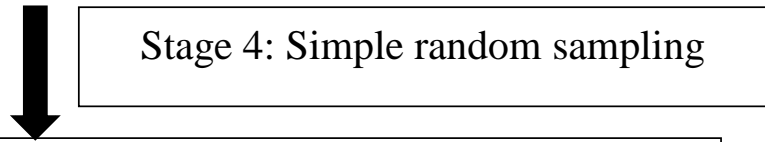

From each house hold one adolescent in chosen, if the house hold has more than one adolescent then the study subject is chosen by the adolescent who is present in household during the visit or by simple random sampling (lottery method) if more than one are present during the visit .

Graph 1: Nutritional Status of the study participants 


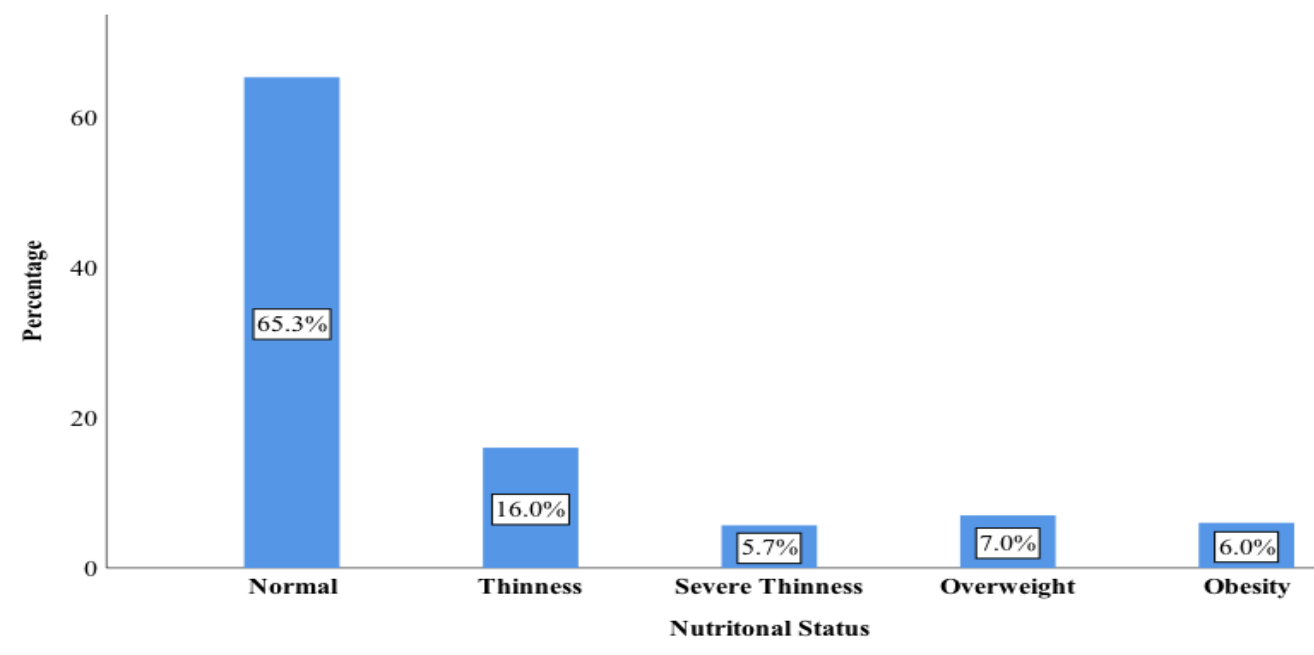

Table 1: HierarchalBinary logistic regression model for predictors of Thinness

\begin{tabular}{|c|c|c|c|c|}
\hline Variable & Categories & $\begin{array}{c}\text { Thinness } \\
\mathrm{n}(\%)\end{array}$ & $\begin{array}{c}\text { Model 1 } \\
\text { AOR (95\%CI) }\end{array}$ & $\begin{array}{c}\text { Model } 2 \\
\text { AOR }(95 \% \mathrm{CI})\end{array}$ \\
\hline \multirow[b]{2}{*}{ Age Groups } & $\begin{array}{c}10-14 \\
\text { (Early Adolescent) }\end{array}$ & $22(33.8)$ & 1 & 1 \\
\hline & $\begin{array}{c}15-19 \\
\text { (Late Adolescent) }\end{array}$ & $43(66.2)$ & $1.6(0.8-2.9)$ & $3.3(1.2-8.8) *$ \\
\hline \multirow{2}{*}{ Gender } & Male & $23(35.4)$ & 1 & 1 \\
\hline & Female & $42(64.6)$ & $2.1(1.6-3.8)$ & $1.9(0.8-4.3)$ \\
\hline \multirow{4}{*}{ Religion } & Hindu & $40(61.5)$ & 1 & 1 \\
\hline & Buddhist & $12(18.5)$ & $0.59(0.2-1.4)$ & $0.2(0.5-0.8)$ \\
\hline & Muslim & $5(7.7)$ & $2.7(0.8-9.5)$ & $1.8(0.3-11.3)$ \\
\hline & Christian & $8(12.3)$ & $1.2(0.4-3.8)$ & $0.4(0.07-2.2)$ \\
\hline \multirow{4}{*}{ Caste } & General & $21(32.3)$ & 1 & 1 \\
\hline & ST & $10(15.4)$ & $1.0(0.3-3.2)$ & $1.2(0.2-6.1)$ \\
\hline & SC & $24(36.9)$ & $2.8(1.3-6.3)$ & $3.0(1.0-9.1) *$ \\
\hline & OBC & $10(15.4)$ & $1.2(0.49-2.9)$ & $2.4(0.7-7.9)$ \\
\hline \multirow{2}{*}{ SES } & Upper Middle and above & $1(1.5)$ & & 1 \\
\hline & Middle class and below & $64(98.5)$ & & 60.0(19.9-183.3.0) \\
\hline \multirow{2}{*}{$\begin{array}{ll}\text { Social Problem in } \\
\text { family }\end{array}$} & Absent & $24(36.9)$ & & 1 \\
\hline & Present & 41(63.1) & & 4.4(1.9-10.2) \\
\hline \multicolumn{2}{|c|}{ Negelkerke $\mathbf{R}^{2}$} & & 0.112 & 0.497 \\
\hline
\end{tabular}

Table 2 :Hierarchal Binary logistic regression model for predictors of Overnutrition/obesity

\begin{tabular}{|c|c|c|c|c|}
\hline Variable & Categories & $\begin{array}{c}\text { Obesity/overweight } \\
\mathrm{n}(\%)\end{array}$ & $\begin{array}{c}\text { Model } 1 \\
\text { AOR }(95 \% \mathrm{CI})\end{array}$ & $\begin{array}{c}\text { Model } 2 \\
\text { AOR }(95 \% \mathrm{CI})\end{array}$ \\
\hline \multirow{2}{*}{ Age Groups } & $\begin{array}{c}10-14 \\
\text { (Early Adolescent) }\end{array}$ & $24(61.5)$ & $3.1(1.4-6.6)$ & $6.6(2.4-18.2)$ \\
\hline & $\begin{array}{c}15-19 \\
\text { (Late Adolescent) }\end{array}$ & $15(38.5)$ & 1 & 1 \\
\hline \multirow{2}{*}{ Gender } & Male & $28(71.8)$ & $3.3(1.5-7.2)$ & $3.1(1.3-7.5)$ \\
\hline & Female & $11(28.2)$ & 1 & 1 \\
\hline \multirow{4}{*}{ Religion } & Hindu & $23(59)$ & 1 & 1 \\
\hline & Buddhist & $14(35.9)$ & $2.1(0.65-2.3)$ & $2.2(0.5-8.8)$ \\
\hline & Muslim & $1(2.6)$ & $0.56(0.06-7.3)$ & $1.0(0.8-13.2)$ \\
\hline & Christian & $1(2.6)$ & $0.4(0.04-3.4)$ & $0.16(0.1-2.3)$ \\
\hline \multirow{4}{*}{ Caste } & General & $11(28.2)$ & 1 & 1 \\
\hline & ST & $13(33.3)$ & $1.2(0.3-5.1)$ & $1.3(0.27-6.8)$ \\
\hline & $\mathrm{SC}$ & $4(10.3)$ & $0.6(0.1-2.4)$ & $2.1(0.4-10.6)$ \\
\hline & OBC & $11(28.2)$ & $3.0(1.1-8.3)$ & $8.8(2.3-33.6)$ \\
\hline \multirow{2}{*}{ Physical activity } & Adequate & $5(12.8)$ & & 1 \\
\hline & Inadequate & $34(87.2)$ & & $10.5(3.3-32.6)$ \\
\hline Weekly & $\leq 3$ times a week & $4(10.3)$ & & 1 \\
\hline
\end{tabular}


JMSCR Vol||07||Issue||03||Page 804-810||March

\begin{tabular}{|c|c|c|c|}
\hline $\begin{array}{l}\text { consumption of } \\
\text { Junk Food }\end{array}$ & $>4$ times a week & $35(89.7)$ & 6.8(2.0-22.6) \\
\hline \multirow{2}{*}{ Daily Screen Time } & $<120$ minutes daily & $6(15.4)$ & 1 \\
\hline & $>120$ minutes daily & $33(84.6)$ & 3.1(1.0-9.6) \\
\hline Nege & rke $\mathbf{R}^{2}$ & & 0.436 \\
\hline
\end{tabular}

Figure 2: ROC curve for the Model 2 for predictor of thinness

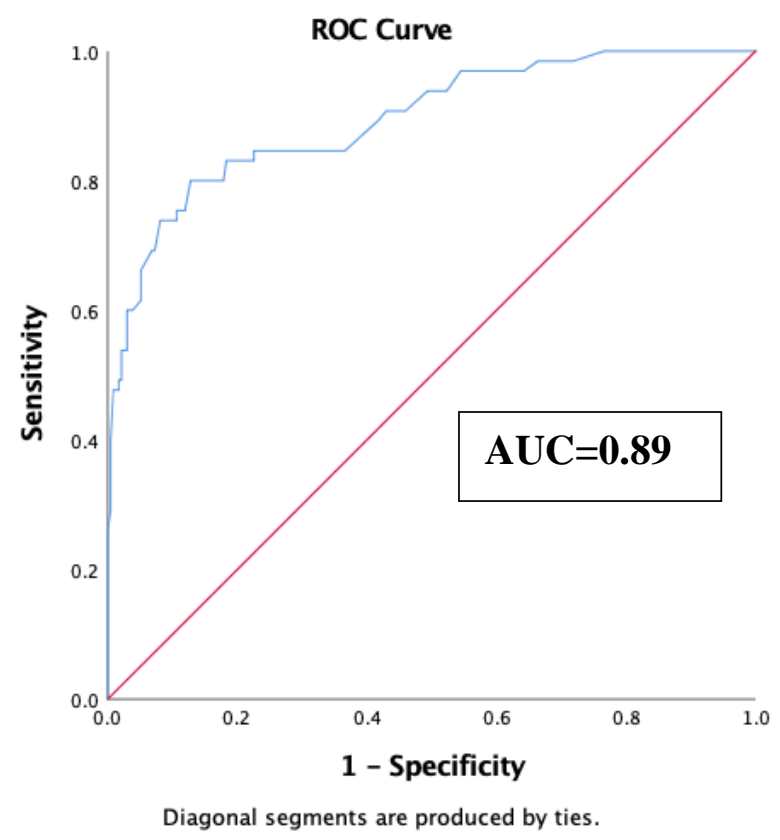

Figure 3: ROC curve for Model 2 for predictors of Overweight/ Obesity 


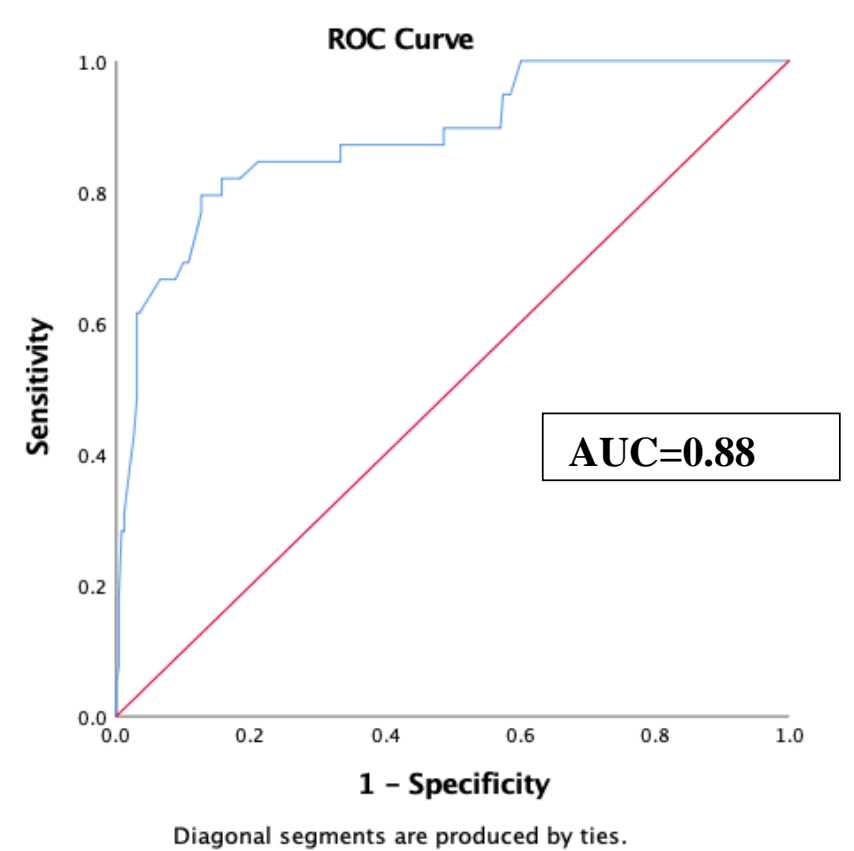

\section{Discussion}

The present study done among adolescents participants residing in the rural field practice area of SMIMS suffered from dual burden of malnutrition. The important predictor for thinness were female, low socioeconomic status of study participant and social problems in the family. On the other hand the important predictor for over nutrition were begin male, inadequate physical activity, increase consumption of junk food and increase daily screen time daily.

The burden of thinness was found to $21.7 \%$ in this study. Studies ${ }^{[7,8,9]}$.done else were in India had documented the prevalence of thinness to range from $15.7 \%$ to $34.3 \%$.

Similarly the prevalence of overweight/obesity as revealed by other studies ranges from $8.13 \%$ to $21 \%$ which is similar to our present study to studies conducted in India ${ }^{[11,12,13] .}$.

Several studies ${ }^{[8,9,10]}$. conducted among adolescent in rural part of India had shown that girls, SC caste, low socioeconomic status and social problem in the family are major determinants for thinness. Studies have also shown that among adolescent $^{[11,12,13]}$. poor life style habits (like inadequate physical activity, increase consumption of junk food and increase daily screen time) are major determinants for overweight/obesity which is similar to finding in our study.

\section{Conclusion}

The present study find that adolescent living in the rural field practices area of SMIMS suffer from dual burden of malnutrition. Female gender and socioeconomic determinants are important ecological factors for thinness while poor life style habits are important predictor for development of obesity and overweight among the study population.

\section{Recommendation}

The prevalence of undernutrition in the study participants was high when compare with overnutrition. There is a need to strengthen the ICDS network to include both adolescent boys and girls. The ICDS should serve as a focal point of nutritional education among the teenage population. The prevalence of obese and overweight adolescent is low when compared to the various part of the country, but with increasing consumption of junk food, and a decrease in physical activity this is going to be a public health problem in future. The ban of high sugar high salt and high energy food in school campus and 
encouraging adolescence participation in physical activity could help tackle the problem.

\section{Limitation}

The present study is carried out only in one rural field practice area, and the result of this study cannot be applied to the entire state of Sikkim. The chemical estimation for various other nutrients level in the blood sample of study participant is not done due to financial constraints. The study participants who are found to be overweight and obese have not been tested for any adverse effects for over nutrition, like deranged lipid profile, or high serum $\mathrm{C}$ reactive protein levels.

\section{Conflict of Interest: None}

\section{References}

1. UNICEF, editor. Adolescence: an age of opportunity. New York, NY: UNICEF; 2011. 138 p. (The state of the world's children).

2. World Health Organization. Adolescent Nutrition: A Review of the Situation in Selected South-East Asian Countries. :96.

3. Gangadharan N. Report of the Working Group on Nutrition For the 12th Five Year Plan (2012 - 2017). New Delhi: Ministry of Women and Child Development Government of India;

4. PMNCH | Government of India launches new health programme for adolescents [Internet]. WHO. [cited 2018 Jul 29]. Available from: http://www.who.int/pmnch/media/events/2 014/india_new_rksk/en/

5. Chandramouli C. Census of India 2011 RURAL URBAN DISTRIBUTION OF POPULATION. New Delhi: REGISTRAR GENERAL \& CENSUS COMMISSIONER, INDIA MINISTRY OF HOME AFFAIRS;

6. Haboubi GJ, Shaikh RB. A comparison of the nutritional status of adolescents from selected schools of South India and UAE : A cross-sectional study. Indian $\mathbf{J}$ Community Med. 2009 Jan 4;34(2):108.

7. Sharma J, Mondal DN. Prevalence of Double Nutrition Burden Among Adolescent Girls of Assam, Northeast India. J Nepal Paediatr Soc. 2014 Oct 30;34(2):132-7.

8. Rai RK, Jaacks LM, Bromage S, Barik A, Fawzi WW, Chowdhury A. Prospective cohort study of overweight and obesity among rural Indian adults: sociodemographic predictors of prevalence, incidence and remission. Open Access. :15.

9. Kshatriya GK. Changing Perspectives of Tribal Health in the Context of Increasing Lifestyle Diseases in India

10. Deka C, Baishya A, Ojah J, Barua K. A study of nutritional status of adolescent girls residing in urban slums of Guwahati city, Assam, India. Int J Community Med Public Health. 2016;2169-73

11. B.t PK, Bengalorkar GM, R D, C M, S R. PREVALENCE OF OVERWEIGHT AND OBESITY AMONG ADOLESCENT SCHOOL GOING CHILDREN (1215YEARS) IN URBAN AREA, SOUTH INDIA -. Int J Curr Res Rev. 2012;4(20):99-105.

12. Braithwaite I, Stewart AW, Hancox RJ, Beasley R, Murphy R, Mitchell EA, et al. The Worldwide Association between Television Viewing and Obesity in Children and Adolescents: Cross Sectional Study. PLOS ONE. 2013 Sep 25;8(9):e74263.

13. Dhobale R, Kumbhar S, Gore A, Waghachavare V, Kadam Y, Dhumale G. A study of food fads and overweight in adolescents from an urban area. Int $\mathbf{J}$ Community Med Public Health. 2016;8137

14. Dey I, Biswas R. Nutritional status of school going adolescents in a rural block of 
Darjeeling, West Bengal, India | Request

PDF [Internet]. Research Gate. 